\title{
TEACHING AGRICULTURAL STUDENTS TO WRITE TECHNICALLY
}

\author{
Alexandra Pett
}

Farming is more than an occupation; it is a way of life. You don't just suddenly decide that you want to be a farmer, take a few courses, apply for a loan, and then set yourself up on a piece of land. You almost have to be born and raised on a farm to know how to succeed. If you look at the statistics, you will see that farming runs in families; in 1981, for example, only 2,300 out of a total of 275,779 census farms were classed as non-family units. 1 Inheritance is the traditional way into farming but even that good fortune may not be enough of a head start in a business that is increasingly complex. Today's farm operators need a far more diversified education than in the past. They must acquire knowledge of and skills in high technology; as well, they are likely to need excellent communication talents in order to market their products. Specifically, what kind of writing is required in the daily life of a farmer? A district agriculturalist has commented that a successful farmer needs letter writing skills that are on the same level of competency as an executive in middle or higher management. 2 Nevertheless, many students whose career goal is to purchase or operate a farm have a deeply ingrained resistance to reading, speaking, and writing which is not easily overcome.

Although textbooks clearly state the value of effective writing skills for scientists and executives and for anyone who wants to succeed in a large corporation, they do not state the case persuasively for welders, mechanics, horse breeders, or farmers. Consider, for example, the following quotation from Scientists Must Write by Robert Barrass:

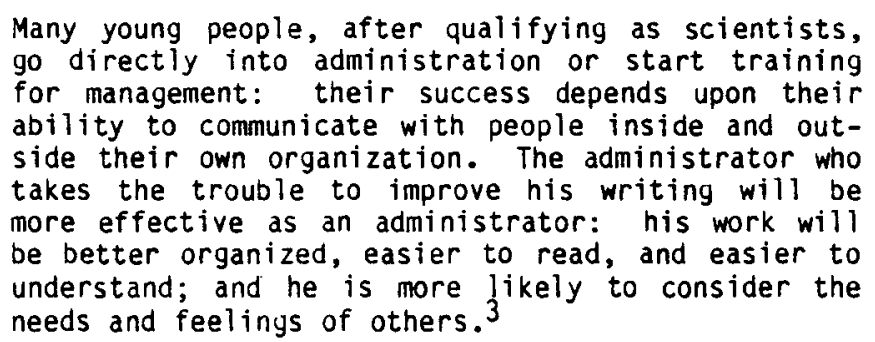

Why a person who writes well is more considerate of the feelings of others is a subtle point that is not explained. It may be easy to demonstrate that communication in general is the basis of daily living, but it is not as easily explained how learning to write a technical report will be important to a farmer. 
The College as Background

Whether they like it or not, all students at 0lds Colleye must take a communications course. Moreover, the writing class reflects the context of the institution. The town of 01 ds is situated 55 miles north of Calgary, half an hour's driving time from Red Deer, in the heart of excellent farmland. The college itself consists of a small campus located on the edye of a 1200-acre farm. Instruction takes place in yreenhouses, mechanics labs, meat labs, stables--all over the farm, in fact. At present the library is housed in a red barn. As much as possible, the communications program reflects the agricultural focus of the campus. The format of the writing class may be structured differently from the format of other ayricultural classes, but the content will not be different because students will be encouraged to use materials from their own technology.

Three years ago we faced the need for a new approach to teaching writing. Because 0lds College is a two-year institution, students have to learn fast, and yet many arrive with a weak background for college courses. They choose vocational training as a way to get around yeneral studies such as English and then find they are confronted with exactly the material they sought to escape! As instructors, we took inventory of the failures of our existing proyram, and then set some objectives: we wanted students to write in a way that is clear, concise, professiona) in appearance, and directed toward a specific audience. We needed a program flexible enough to accommodate different skills levels, and flexible enough to meet the needs of students in different ayriculturerelated disciplines. Focusing on a self-paced developmental approach, we eliminated formal instruction in grammar, permitted use of split page and even point format under headings, and encouraged the use of visuals. As our expectations of our students increased, so also did their level of achievement.

\section{Recognizing Self-Defeating Attitudes}

As sociologists tell us, beliefs, values, and attitudes are shaped by cultural forces which play an important part in learning. Social backyround is an important factor in the way people learn and in the way we teach people to write. When you are teaching writing, you are drawing on all aspects of your own background, and inevitably you come up against the total educational reserves of the student. For many students with farm backgrounds, the learning that takes place in a writing class can be a painful process of resetting personal priorities. Some must alter their ways of looking at experience. In general, they have to offset the social conditioning that has led them to regard. writing as superfluous to "real life." 
Recognizing self-defeating attitudes is a slow process. When students learn to become more articulate in a speech class at the same time as they are taking a writing class, their progress is likely to be faster in both speaking and writing. For example, learning about the speaker's impact on the audience has an important correlation to audience analysis in technical writing. How much information can an uninformed listener absorb? When students appreciate that communication is a two-way process, they bring that knowledge to the writing situation and they are likely to recoynize also the need for clarity in defining a problem. The group interaction of the speech class further provides a background for peer analysis in technical writing sessions. To illustrate the differences and similarities between oral and written communication, we ask them to use the same technical material for a report as for a speech.

To nelp them improve weak reading skills and to find out about agricultural writing, students are asked to find material in their own field that they have enjoyed reading. They must submit a duplicated article, essay, or report with answers to two questions: What contribution does your selection make to your field of agriculture? Why is this an example of yood writing? Many farmers are obsessive readers of advertisements, pamphlets, magazines, and newsletters, but often they do not digest the information wisely. Classroom reading experiments tended to support this generalization. We drew the following conclusions from the materials which our students chose to read:

1. Technical writing in the field of popularized ayriculture is much like journalism. It is designed for quick reading; it contains simple visuals, such as diagrams of how to complete a process and pictures of equipment. Key points are repeated. Sections of dialogue are interspersed with simplified definitions.

2. Despite technical content, student selections focused on people and animals. Even articles on agricultural machinery included reference to operators failing to remember to service equipment according to manufacturers' directions. Students identified the major purpose of this kind of writing as problem solving: given various possibilities, which choice would any given farmer make?

\section{Kinds of Agricultural Writing}

This first step in our writing proyram is important because it draws students into the writing process, forces them to consider how writers present information, and makes them aware that there are various different styles and levels of expertise in agricultural writing. Most students choose articles from such publications as Grainews, but they 
soon become aware that other journals have a more scientific focus and are designed for a different reading audience. From hard-to-read scientific abstracts of completed research to attempts to explain scientific theory to the layman farmer, agricultural writing reflects the diversity of agriculture as a hybrid discipline. Moreover, agricultural writing has an international scope: "Because the subject content of 'agriculture' is broadly applied biology, the pattern of production and publication of reports is worlg-wide on a zonal or regional basis rather than purely national." 4 In examples for discussion in class, there are obvious variations in writer competency. (See Appendix.) Students pick up on areas for improvement; for example, sentences in paragraphs can be reordered to create a sharper effect, or classification can be clearer so that the paragraph flows, or transitional aids between sentences and paragraphs can assist the reader.

\section{Establishing an Objective Tone}

As soon as students understand the principles of good writing, such as careful selection of focus and detail, use of visualization, and use of time/space sequence, they differentiate between technical writing and other kinds of writing. However, many continue to have difficulty in establishing the objective tone necessary for technical writing. Although they recognize the importance of conclusions based on factual evidence, they cling to the personal pronoun "I". Presenting technical information in a clear, logical fashion, the task of the technical writer, involves first of all the ability to move beyond personal experience, and secondly, the ability to organize external evidence. How far to go in the direction of eliminating the writer's voice, however, is a matter for debate.

Robert Bly and Gary Blake begin their text Technical Writing: Structure, Standards, and Style with a controversial quotation from Kurt Vonnegut:

\footnotetext{
Newspaper reporters and technical writers are trained to reveal almost nothing about themselves in their writing. This makes them freaks in the world of writers, since almost all of the other inkstained wretches in that world reveal a lot about themselves to the readers. 5
}

Without commenting on Vonnegut's irony, they go on to say that technical writing must have an objective tone; "the technical content, not the author's voice, is the focal point." 6 Actually, these comments are misleading because they suggest that technical writing is all cast in the same key or written without substantial variations in tone, even within the same article. For example, an article on soils in Grainews is written in the first person: "I noted some confusion in terminology concerning denitrification in the November issue of Grainews, so I 
thought we should clear up some of these matters ... By minera? nitrogen, I mean either nitrate or ammonium. This process is called mineralization. It can take place in several steps and one of these steps is the conversion of ammonium to nitrate. This process is referred to as nitrification." 7 of course, Bly and Blake do not mean that use of the personal pronoun I is a sign of subjectivity; nevertheless, the discussion on objectivity in relation to audience and purpose does not adequately cover the variations in the writer's voice or the effect of social conditioning on selection of data. It seems obvious that, although there is an important distinction between definitions of technical writing that focus on content and definitions of writing technically that focus on approach, in general good writing reflects control over material but not the total elimination of the writer's voice and personality. In fact, recent definitions of technical writing stress the human relationship between writer and reader. The humanizing effect of language is stressed in the following definition: "Technical writing is writing that accommodates technology to the user." 8 Textbooks also adopt a user-friendly tone, relying on "we" or "our" to suggest a tolerant, sympathetic writer guiding the learner through difficult and unfamiliar territory.

In agriculture the problem of establishing an objective tone is most evident in writing about animals. To farmers, relationships with animals are often as important as relationships with people. (When I told my students interested in equines that they were writing about horses as people, they were at first mystified and then furious because of the implied criticism.) We tell students to delete personification: "Scientists should not endow inanimate things or even living organisms other than people, with human attributes." 9 Some texts insist further that all metaphors and other figures of speech should be eliminated: "The man in the street may say that his car does not like a steep gradient or that the sun is trying to break through the clouds, but the scientist should not allow such expressions of human emotion to creep into his writing." 10 On a practical level, however, writers go as far as they can in the direction of bringing facts about animals to "life" for the reader. Sustained analogy (as in the appendix example of a telephone switchboard to explain a dog's sensual reactions) abounds in writing about animals. Moreover, even writing about machines has a human context. In robotics manuals robots are described as if they were human.

0bjectivity is created, overall, through a careful use of factual language. Even so, it is hard to find writing with absolutely no hint of opinion. Instead, there are a number of gradations in objectivity, from purely factual to factual writing tinged with opinions to purely opinionated writing. For example, this description of an animal by Mark Twain is both opinionated and individualistic: "The coyote is a long, slim, sick and sorry-looking skeleton, with a gray wolf-skin stretched over it, a tolerably bushy tail that forever sags down with a despairing expression of forsakenness and misery, a furtive and evil eye, and a long, sharp face, with slightly lifted lip and exposed teeth." 11 "If you 
compare this with a description of a coyote, based on facts, from an encyclopedia, you find that the tone is more objective but that opinionated judgements exist: "An intelligent animal with a reputation for cunning and swiftness, the coyote has been persecuted by man because of the damage, greatly overrated, done by individuals that sometimes prey on domestic or game animals." 12

On the level of human relations, the learning experience involved in achieving objectivity in writing can have widespread effects. Because farmers do not make a clear split between their career and their family life, we allow our students to imagine situations that have a personal focus. Living and working in the same environment requires a certain determination not to let conflict with family members interfere with work. We try to incorporate the ability to look at yourself without feelirg defensive as a key part of objectivity. The writing class, thus, has links to learning life skills.

\section{Sample Assignments}

When students have learned to describe the anatomy of a horse or the stomach of a cow, using reader interest and establishing a reader/ writer contact, without resorting to personification, they are ready to tackle the critical insight necessary in report writing. What does analysis mean? How do you move from simple dissection to enumeration of causes and statement of root principle? Moreover, are these relevant considerations for the material selected? In the following two sample assignments we ask students to use their agricultural background, to consider possible arganizational patterns, and to look at some of the structures, models, formats of technical writing.

Most farms operate on borrowed capital. Inevitably, farmers have to fill in applications for bank loans. Government publications stress that applicants must document how the money will be used and paid back. Since dealing with the bank is a key factor in success in farming, we use that context for our proposal report. Students in agribusiness do well in this assignment because they receive training in cost analysis; other students, in such disciplines as horticulture, also pick up on the need for financial planning. The proposal report is versatile in other ways too. It can be applied to academic situations as well as community projects.

Lack of understanding of material is often a problem in technical writing submitted by students, especially in the area of agricultural mechanics. In our recommendation report based on comparative data we look for comprehension of different technology and equipment. Although we also use academic report style (with abstract, summary, letter of transmittal, and bibliography), we find that the recommendation report as a concise package allows students to integrate materials from their discipline of study with the way of approaching writing which they have learned in our course. 
In presenting both assignments, we approach instruction with a combination of product/process philosophy. In the classroom, examples of student reports are provided, as well as examples from textbooks, but we use structural models of formats for discussion purposes only. In the future we would like to use better theoretical models and more reference to actual situations in agriculture. As Victoria Winkler states in her essay "The Role of Models in Technical and Scientific Writing", there is a real need to combine theory and practice: "The challenge facing teachers of technical and scientific writing in the eighties is to develop an inter-disciplinary problem-solving rhetorical theory to improve the teaching of technical, scientific, and professional writing while also guiding research in communication theory." 13 The process approach to teaching technical writing offers many exciting possibilities which are as yet unexplored. Winkler's discussion of the use of analogues, of the difference between structural and inventional models, reveals how the use of language and concepts is an integral part of the composing process. In our program, in its present stage of development, we are often forced to take a more strictly practical perspective.

Building on success, students move from short reports to manuals and amplified definition. Within 15 weeks, they progress from a oneparagraph memo to a 12-page format. Their ability to tackle a research project has also developed. To indicate clearly how assessment is made, we use marking sheets for each assignment. The criteria and the weighting cover such general categories as critical analysis, originality of thought, organization, tone, and stylistic correctness. In this way it is far easier for students to see how they are evaluated and how they should improve than it is in many other kinds of writing courses. Moreover, students coming from other kinds of learning environments comment favourably on this aspect of technical writing.

Recent research (1985) on the teaching of writing to agricultural students indicates that peer evaluation of writing assists students in learning course content in such subjects as cropping systems, agricultural climatology, agronomic research and crop physiology. 14 Eventually, we would like to use writing across the curriculum as a way of improving students' writing skills on a campus-wide basis.

\section{Benefits of Technical Writing for Agricultural Students}

One positive aspect of technical writing for students who are vocationally oriented is the development of awareness of the need to communicate with a purpose in mind. Considerations such as audience and intent apply directly to the work environment. The demand for professionalism is at first intimidating and then confidence building as students realize that they can make dramatic improvement if they are committed. In fact, the confidence gained from the communications course often proves a crucial preliminary step in making a conscious choice of occupation within agriculture. 
Other benefits of the writing class include higher achievement in other courses and improved self-image. Many of our students will be required to return to communities where their leadership is much needed; the ability to think critically which is part of a writing course helps them enormously to focus their energy on decision making. We encourage them to set long-range goals for further self-improvement. For some, the training in the two-year college leads to a university program in agriculture.

For those who will return to farms, perhaps in isolated rural areas, learning to write effectively is a potential link to the outside world. The student who has never worked for anyone except his father has difficulty writing a letter to a supervisor in a city-based engineering company; he has no concept of the kind of relationship which might exist between the two people involved and so cannot achieve a plausible tone. Writing business letters inevitably helps to conceptualize different social settings. Moreover, changes in the technology of farming will affect all aspects of daily life. The family unit is forced to turn outward. To communicate with other people in the industry, those in agricultural occupations may find that writing must become part of everyday business.

A recent report on agricultural education in Alberta speaks of agriculture as "so complex, so pervasive, that we often forget how it affects, in fact how it controls, all of our lives." 15 A list of agricultural occupations includes machinists, animal health technicians, turf managers, meat cutters, florists, and land agents, without even mentioning livestock producers or grain farmers. And yet agriculture needs a stronger voice, both nationally and internationally. Training students in technical writing eventually improves their ability to express informed opinions on issues that are vital to human continuty.

NOTES

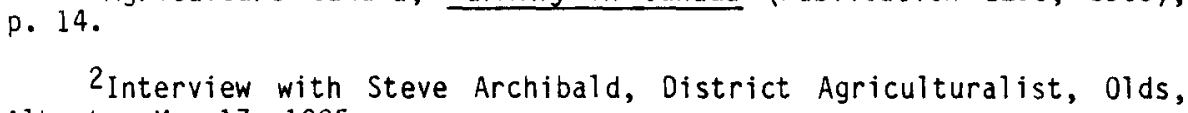

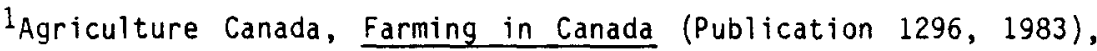
Al berta, May 17, 1985.

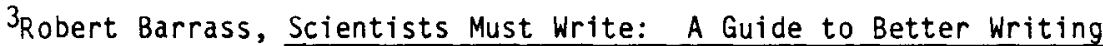
for Scientists, Engineers and Students (New York: Chapman and Hall, 1978), p. 17.

4F.C. Hirst and A.G. Myatt, "Agriculture and Food," in Use of Reports Literature, ed. Charles Auger (London: Butterworths, 1975), pp. $98,99$.

5Robert $W$. Bly and Gary Blake, Technical Writing: Structure, Standards, and Style (New York: McGraw-Hill, 1982), p. I. 
$681 y$ and 81 ake, p. 2. 1983.

7Les Henry, "A Trip Around the Nitrogen Cycle," Grainews, January,

8David N. Dobrin, "What's Technical About Technical Writing," New Essays in Technical and Scientific Communication: Research, Theory, Practice, ed. Paul V. Anderson (Farmington, N.Y.: Baywood, 1983), p. 242 .

$9_{\text {Barrass, p. } 31 .}$

10 Barrass, pp. 31,32 .

11 Mark Twain, Roughing It (New York: Harper, 1871), p. 48.

12Encyclopedia Britannica, III (1974), pp. $211,212$.

13 Victoria M. Winkler, "The Role of Models in Technical and Scientific Writing," in New Essays in Technical and Scientific Communication: Research, Theory, Practice, p. III.

${ }^{14}$ Thomas B. Brumback, "Peer Response: An Effective Way to Incorporate Writing Into the Classroom," NACTA Journal (March 1985), pp. 77-81.

$15 \mathrm{Big} A$ Agriculture, unpublished document presented to the Agricultural Caucus, Government of Alberta, 1983 (c. $01 d s$ College, $01 \mathrm{ds,}$ Alberta), p. 1 .

Alexandra Pett is Coordinator of Liberal Arts at 01 ds College, Alberta. She presented this paper at the CATTW Conference, Université de Montréa 1, May 1985. 
APPENDIX

SAMPLES OF AGRICULTURAL WRITING

Writing About Soils

1. Let's pretend we are a granule of ammonium nitrate (34-0-0) and that we have been applied to the soil. Ammonium nitrate is made up of an ammonium (NG4+) ion which carries a positive charge and nitrate (NO3-) which carries a negative charge. The word ion simply refers to a charged particle. Let's first assume we are a nitrate ion and flip once around the cycle. ("A Trip Around the Nitrogen Cycle" by Les Henry, Grainews, January 1983)

2. Crusting soil surfaces with vesicular pores occur in arid and semiarid regions of the world where herbaceous vegetation is sparse. Morphological properties of crusting surfaces can impair seedling emergence and plant establishment. This study evaluated site preparation and seeding methods and species useful for encouraging successful stand establishment in such soils. Plowing to prepare a seedbed reduces seedling emergence on some soils but increased plant establishment on all soils. More seedlings emerged and established on non-crusting coppice soil beneath shrubs than on crusting interspace soil between shrubs. Crested wheatgrass was the most successful species followed closely by squirreltail and distantly by Thurber needlegrass and fourwing saltbush. (Journal of Range Management, Vol. 35, No. 35, May 1982, p. 282)

Writing About Plants

Plant cell walls provide the structural framework for plants. They completely enclose the cells which are the sites of photosynthesis, respiration and other metabolic activities. The cell plant constituents, i.e. proteins, sugars, and starch, are valuable nutrients for livestock; but the same cell constituents are the immediate culprits in causing pasture bloat. There are several reasons for implicating the cell constituents in a pasture bloat. First, they are ideal nutrients for the rumen bacteria that digest the cell constituents. In so doing, they produce a substantial volume of gas. Secondly, this gas is retained within the rumen fluid. (Canada Agriculture, Vol. 24, No. 3, p. 7)

Writing About Animals

Returning to our telephone analogy, a word (stimulus) spoken into the mouth-piece (receptor) is converted into an electrical impulse that travels over a wire (afferent fiber) to "central" where a switchboard connection (synapse) is made with an outgoing wire (efferent fiber) to the earpiece (effector) of another phone. 
Receptors are specialized for various types of stimuli: heat, cold, pressure, touch, smell, light, taste etc., the number of which in any given area determines how sensitive an animal may be to a given stimulus. Thus dogs have a highly developed sense of smel1, which can be related to the many receptors they have in the olfactory area of the nasal cavity. (Animal Hospital Technology, 1971, p. 26)

\section{Writing About Machines}

1. Overall, the New Holland Twin Rotor 95 is a superior machine over the John Deere 8820 Conventional machine for the following reasons:

1. The threshing action of the rotors is much more gentle causing less grain shelling and crackage.

2. Threshing and separating occur the whole length of the rotors plus at the rear discharge beater.

3. There is less power loss because of the precision timing of the rotors and because each rotor is threshing and separating grain.

4. More grain is saved through the combined operations of the threshing system.

5. A cleaner sample of grain can be put in the tank.

6. An increase of 20 bushels per full grain tank can be gained over and above the John Deere 8820 conventional machine.

(Student Assignment)

2. The Robot's eyes, ears, and other senses are provided by the circuit boards. The sense board measures light and noise levels for the CPU. Ultrasonic ranging boards transmit and receive the signal to measure the distance to an object in front of the transmitter. The motion detect board senses amplitude modulation of its ultrasonic signal whenever there is motion nearby. The Robot's clock and calendar are located on the I/0 board and are available for applications requiring the measurement of time. (ET-18: Technical Manual, 1983, p. 71) 